\title{
Apolipoprotein E Genotype and Sex Influence Glucose Tolerance in Older Adults: A Cross-Sectional Study
}

\author{
Angela J. Hanson ${ }^{a, b}$ William A. Banks ${ }^{a, b}$ Hector Hernandez Saucedo ${ }^{c}$ \\ Suzanne Craft $^{c}$ \\ a Department of Medicine, University of Washington School of Medicine, and ${ }^{b}$ Geriatric \\ Research, Education, and Clinical Center, Veterans Affairs Puget Sound Health Care System, \\ Seattle, Wash., and 'Sticht Center on Aging, Department of Internal Medicine, Wake Forest \\ University School of Medicine, Winston-Salem, N.C., USA
}

Key Words

Apolipoprotein $\varepsilon 4$ allele $\cdot$ Glucose intolerance $\cdot$ Alzheimer's disease $\cdot$ Oral glucose tolerance test

\section{Abstract}

Background: Glucose intolerance and apolipoprotein $\varepsilon 4$ allele (E4+) are risk factors for Alzheimer's disease $(A D)$. Insulin sensitizers show promise for treating $A D$, but are less effective in E4+ individuals. Little is known about how the APOE genotype influences glucose metabolism. Methods: Cross-sectional analysis of 319 older adults who underwent oral glucose tolerance tests; a subset had insulin, amyloid beta $\left(A \beta_{42}\right)$, and Mini Mental Status Examination. Glucose and insulin patterns with respect to cognitive diagnosis, E4 status, and sex were examined with analysis of covariance and Pearson correlation. Results: People with cognitive impairment had higher fasting insulin levels. E4 status did not affect fasting glucose values, whereas men had higher fasting glucose levels than women. E4+ men had the lowest and E4+ women had the highest glucose levels, compared to E4- groups; insulin did not differ by sex or E4 group. E4 status and sex moderated correlations between metabolic measures and AD risk factors including age and $A \beta$. Conclusions: Insulin resistance was associated with cognitive impairment, and sex, E4 status, and glucose values are interrelated in older adults at risk of AD. Understanding glucose metabolism for different APOE and sex groups may help elucidate differences in therapeutic responses. 
Hanson et al.: Apolipoprotein E Genotype and Sex Influence Glucose Tolerance in Older Adults: A Cross-Sectional Study

\section{Introduction}

Carriage of the $\varepsilon 4$ allele of the APOE gene (E4+) and states of glucose intolerance and insulin resistance are risk factors for Alzheimer's disease (AD) [1-4]. Individuals with AD demonstrate low levels of brain insulin and increased markers of brain insulin resistance, irrespective of E4 status $[3,5,6]$. It is known that prolonged peripheral hyperinsulinemia is associated with lower insulin levels in the cerebrospinal fluid (CSF); however, this inverse relationship between plasma and brain insulin is not as strong in E4 carriers [6-9]. In addition, E4+ individuals with AD are less likely to benefit from insulin-related therapeutics [10-14].

Little is known about whether the APOE genotype modulates peripheral glucose and insulin metabolism, and subsequently insulin-related AD pathology. As the 2-hour oral glucose tolerance test (OGTT) is a sensitive measure of glucose tolerance, we constructed a convenience sample of older adults with a known APOE genotype whose glucose and insulin levels were measured during an OGTT. This study was designed to investigate whether the E4 status moderated OGTT values, and to determine whether the relation between glucose intolerance and $\mathrm{AD}$ risk factors was influenced by $\mathrm{E} 4$ status. We also wanted to examine whether sex played a role in the relation between E4 status and glucose tolerance, as sex influences the $\mathrm{AD}$ risk of $\mathrm{E} 4$ status, and the interaction of sex and $\mathrm{E} 4$ status influence responses to intranasal insulin in $\mathrm{AD}[15,16]$.

Here, we show that individuals with cognitive impairment $(\mathrm{CI})$ have higher levels of fasting insulin, consistent with the known link between insulin resistance and AD. We also show that E4 status influences glucose tolerance, and the relationships between OGTT glucose values, age, and plasma amyloid- $\beta_{42}\left(A \beta_{42}\right)$. Furthermore, these relationships are moderated by sex, with E4+ women displaying higher OGTT glucose values and E4+ men lower glucose levels, compared to E4- groups. Understanding how the APOE genotype influences glucose and insulin metabolism may help us understand the pathogenesis of AD, which may involve both peripheral and brain insulin resistance factors.

\section{Methods}

\section{Participant Characteristics}

The query of a de-identified database of participants who were enrolled in a variety of studies regarding metabolism and cognition revealed 319 people who had undergone an OGTT as part of a baseline screening evaluation with glucose values at 0,60 , and $120 \mathrm{~min}$, and for whom data were available regarding age, BMI, APOE genotype, and cognitive diagnosis. Cognitive diagnoses included normal cognition (NC), mild CI (MCI), and early AD, as determined in a consensus conference by a team of neuropsychologists and physicians. Mini Mental Status Examination (MMSE) scores, fasting plasma $\mathrm{A} \beta_{42}$, and insulin were available for a subset of participants. All participants for this query were free of diabetes and were not taking diabetes medication. In addition, all women included in this query were postmenopausal.

\section{Measures of Glucose, Insulin, $A \beta_{42}$, and APOE Genotype}

Participants underwent a 75-gram 2-hour OGTT after an overnight fast. Blood samples were obtained through an intravenous catheter and plasma glucose was measured using the glucose oxidase method (Beckman Instruments, Fullerton, Calif., USA) [17]. All participants had glucose values measured at 0,60, and 120 min. For some individuals, insulin was measured via radioimmunoassay as described by Kuzuya et al. [18] for three time points (202 individuals for fasting insulin, 141 individuals for 60 and $120 \mathrm{~min}$ ). For those who had fasting 
Hanson et al.: Apolipoprotein E Genotype and Sex Influence Glucose Tolerance in Older Adults: A Cross-Sectional Study

Table 1. Baseline demographics

\begin{tabular}{lccrr}
\hline & \multicolumn{3}{c}{ E4- } & \multicolumn{2}{l}{ E4+ } \\
\cline { 2 - 5 } & women & men & women & \multicolumn{1}{l}{ men } \\
\hline Number (\% CI) & $96(58)$ & $112(56)$ & $60(67)^{\mathrm{a}}$ & $51(78)^{\mathrm{a}}$ \\
Age, years & $68.1 \pm 9.2^{\mathrm{b}}$ & $72.6 \pm 8.1^{\mathrm{b}}$ & $67.1 \pm 7.5^{\mathrm{c}}$ & $72.1 \pm 8.6^{\mathrm{c}}$ \\
BMI & $28.1 \pm 5.6$ & $28.6 \pm 3.8$ & $27.2 \pm 5.4$ & $27.5 \pm 4.6$ \\
MMSE score & $27.4 \pm 3.6$ & $27 \pm 3$ & $26.4 \pm 4.8$ & $25.8 \pm 3.6$ \\
$\quad(\mathrm{n}=142)$ & & & & \\
$\mathrm{A} \beta_{42}(\mathrm{n}=123)$ & $57.1 \pm 45.2$ & $60.2 \pm 42.9$ & $44.7 \pm 34$ & $43.7 \pm 24.2$ \\
\hline
\end{tabular}

Data are given as mean \pm standard deviation unless indicated otherwise. ${ }^{a}$ More CI in the E4+ group than in the E4- group $\left(\chi^{2} \mathrm{p}\right.$ value 0.036). ${ }^{b}$ E4- men older than E4- women $(p=0.0002) .{ }^{c} E 4+$ men older than E4+ women $(p=0.0022)$.

insulin, the homeostasis model assessment insulin resistance (HOMA-IR) index was calculated with the following formula: fasting insulin (in $\mu \mathrm{U} / \mathrm{ml}$ ) $\times$ fasting glucose (in $\mathrm{mg} / \mathrm{dl}$ ) $/ 405$ [19].

Plasma $\mathrm{A} \beta_{42}$ was measured with an ELISA technique using a rabbit polyclonal antibody to capture nonspecific $A \beta$ followed by an $A \beta_{42}$-specific $6 \mathrm{E} 10$ mouse monoclonal antibody (Signet Laboratories, Dedham, Mass., USA). APOE testing was conducted by the genotyping core of the University of Washington Alzheimer's Disease Research Center. In brief, DNA was extracted from buffy coat preparations and subjected to PCR amplification with primer sequences and methods as per Hixson and Vernier [20].

\section{Statistics}

Baseline measures were compared among groups using $\chi^{2}$ statistics and analyses of covariance (ANCOVAs), with cognitive diagnosis (NC or CI), E4 status (E4+ or E4-), and sex as categorical variables, and age and BMI as covariates. When applicable, $p$ values from the type III sum of squares were given (SAS 9.3, Cary, N.C., USA). Time point outcomes were analyzed by repeated-measures ANCOVA, with cognitive diagnosis, E4 status, and sex as categorical variables, glucose and insulin as dependent variables, time $(0,60$, and $120 \mathrm{~min})$ as the repeated factor, and age and BMI as covariates. Correlations were analyzed using Pearson statistics in SAS, and we examined all scatter plots to ensure no statistical outliers underlied the findings.

\section{Results}

\section{Baseline Demographics}

Table 1 shows the baseline demographics of the 319 participants by E4 status (positive or negative) further subdivided by sex. Comparisons between groups were made using $\chi^{2}$ tests for the categorical variable of cognitive diagnosis (NC and CI, which included both MCI and AD), and ANOVA for the continuous variables. There were more individuals with $\mathrm{CI}$ in the E4+ compared to the E4- groups $\left(\chi^{2}, \mathrm{p}=0.036\right)$; however, the average MMSE scores were similar. For clarity, we combined the cognitive groups for the baseline demographics, as for most analyses cognitive diagnosis did not affect results. The men were significantly older than the women ( $\mathrm{E} 4-$ men $>\mathrm{E} 4-$ women, $\mathrm{p}=0.0002$; $\mathrm{E} 4+$ men $>\mathrm{E} 4+$ women, $\mathrm{p}=0.0022$ ). BMI and plasma fasting $A \beta_{42}$ did not differ among groups. 
Hanson et al.: Apolipoprotein E Genotype and Sex Influence Glucose Tolerance in Older Adults: A Cross-Sectional Study

Table 2. Fasting glucose, fasting insulin, and HOMA-IR, by cognitive groups, then further divided by E4 and sex groups

\begin{tabular}{|c|c|c|c|c|c|c|c|c|c|c|}
\hline & \multicolumn{5}{|l|}{ NC } & \multicolumn{5}{|l|}{ CI } \\
\hline & \multirow[t]{2}{*}{ all NC } & \multicolumn{2}{|l|}{ E4-NC } & \multicolumn{2}{|l|}{$\mathrm{E} 4+\mathrm{NC}$} & \multirow[t]{2}{*}{ all CI } & \multicolumn{2}{|l|}{ E4-CI } & \multicolumn{2}{|l|}{$\mathrm{E} 4+\mathrm{CI}$} \\
\hline & & women & men & women & men & & women & men & women & men \\
\hline Glu0 & $101 \pm 1.3$ & $97.6 \pm 1.9$ & $104.8 \pm 1.7$ & $102 \pm 2.6$ & $103.6 \pm 3.6$ & $100.5 \pm 0.9$ & $98.1 \pm 1.6$ & $103 \pm 1.5$ & $99.4 \pm 1.9$ & $101.5 \pm 1.9$ \\
\hline Ins0 & $11.7 \pm 0.9$ & $11.4 \pm 1.3$ & $15.3 \pm 1.1$ & $10.5 \pm 1.9$ & $9.5 \pm 2.7$ & $15.6 \pm 0.6$ & $14.9 \pm 1.2$ & $15.3 \pm 1$ & $16.2 \pm 1.4$ & $16.1 \pm 1.3$ \\
\hline HOMA & $3 \pm 0.3$ & $2.9 \pm 0.3$ & $3.9 \pm 0.3$ & $2.6 \pm 0.5$ & $2.6 \pm 0.7$ & $3.9 \pm 0.2$ & $3.6 \pm 0.3$ & $3.9 \pm 0.3$ & $4 \pm 0.4$ & $4.2 \pm 0.3$ \\
\hline
\end{tabular}

Glu0 = Fasting glucose; Ins 0 = fasting insulin. Data are given as mean $\pm \mathrm{SEM}$, glucose in $\mathrm{mg} / \mathrm{dl}$, insulin in $\mu \mathrm{U} / \mathrm{ml}$. All values are adjusted for age and BMI. For Glu0, we found an overall sex effect (men > women, $\mathrm{p}=0.013$ ), and least-squares means comparisons showed that this was true for E4- NC men versus E4- NC women ( $p=0.0046)$ and for E4- CI men versus E4- CI women ( $p=0.027)$. E4+ groups did not show a significant sex effect. For Ins 0 , we found an overall cognitive diagnosis effect ( $\mathrm{CI}>\mathrm{NC}, \mathrm{p}=0.0005)$, and a cognitive diagnosis $\times \mathrm{E} 4$ effect $(\mathrm{p}=0.038)$, and least-squares means comparisons showed that those with $\mathrm{CI}$ had higher fasting insulin levels than those with NC for all E4 $\times$ sex groups except for E4- men. For HOMA-IR, we found an overall cognitive diagnosis effect $(\mathrm{CI}>\mathrm{NC}, \mathrm{p}=0.0011)$, and a cognitive diagnosis $\times \mathrm{E} 4$ effect $(\mathrm{p}=0.049)$. Similar to fasting insulin, examination of least-squares means revealed that those with $\mathrm{CI}$ had higher or a trend toward higher HOMA-IR levels than those with NC for all E4 $\times$ sex groups, except for E4- men.

\section{Fasting Measures of Glucose and Insulin}

All participants had measures of fasting glucose. A subset also had fasting insulin $(\mathrm{n}=$ 202), and for those participants, we calculated the HOMA-IR index, with higher numbers denoting more insulin resistance [19]. We examined whether cognitive diagnosis, E4 status, or sex influenced fasting measures using ANCOVA, and these data are presented by cognitive group ( $\mathrm{NC}$ or $\mathrm{CI}$ ), and then further subdivided into $\mathrm{E} 4$ and sex groups (table 2). The covariates of age and BMI were found to be significant in the fasting glucose analysis (age $p=0.002$, BMI $\mathrm{p}=0.009$ ); therefore, they were included in all subsequent analyses.

We did not find any significant differences in fasting glucose values by cognitive diagnosis or by $\mathrm{E} 4$ status (diagnosis $\mathrm{p}=0.3, \mathrm{E} 4 \mathrm{p}=0.6$ ). However, men showed higher fasting glucose values than women ( $\mathrm{p}=0.013)$, and this appeared to be driven by the E4- groups (E4- NC men > E4- NC women, $p=0.0046$, and E4- CI men $>$ E4- CI women, $p=0.027$ ). Those with $\mathrm{CI}$ had higher fasting insulin levels than those with $\mathrm{NC}(\mathrm{p}=0.0005)$, which is similar to past work showing that AD or its precursor MCI has a form of insulin resistance [21]. For fasting insulin, we also noted a cognitive diagnosis $\times \mathrm{E} 4$ interaction $(p=0.047)$. Examination of the means revealed that individuals with $\mathrm{CI}$ had higher fasting insulin levels than those with NC for all E4 $\times$ sex comparisons ( $p<0.05)$ except for E4- men $(p=0.9)$. The HOMA-IR results paralleled those of fasting insulin, with a higher HOMA-IR for those with CI compared to NC ( $p=0.0011)$, and a cognitive diagnosis $\times E 4$ interaction $(p=0.049)$ such that those with CI had higher or a trend toward higher HOMA-IR levels than those with NC for all E4 $\times$ sex groups ( $p$ values all $<0.1$ ) except for E4- men ( $p=0.9$ ).

Given that the CI group encompassed people with MCI as well as with established AD, a separate analysis for fasting insulin was conducted with $\mathrm{NC}, \mathrm{MCI}$, and $\mathrm{AD}$ as three separate groups, adjusting for age and BMI. Once again, those with NC had lower insulin values than those with any $\mathrm{CI}$; no differences were noted between the $\mathrm{MCI}$ and the AD groups (NC $12.8 \pm$ $0.8, \mathrm{MCI} 15.4 \pm 0.7, \mathrm{AD} 16 \pm 1.1, \mathrm{NC}<\mathrm{MCI}$ and $\mathrm{AD}, \mathrm{p}<0.05, \mathrm{MCI}$ and $\mathrm{AD}$ comparison, $\mathrm{p}=0.6$ ). Therefore, the MCI and $\mathrm{AD}$ groups were combined.

\section{OGTT Glucose and Insulin}

Next, we examined glucose and insulin values obtained during an OGTT using repeatedmeasures ANCOVA with cognitive diagnosis, E4 status, and sex as class variables, glucose at the time points 0,60 and $120 \mathrm{~min}$ as repeated factors, and age and BMI as covariates. The results are displayed graphically in figure 1 , and the adjusted measures are shown in table 3 . 
Fig. 1. Graphical representation of glucose (a) and insulin (b) values, by E4 status and sex. p values and explanations are given in the text, and in table 3.

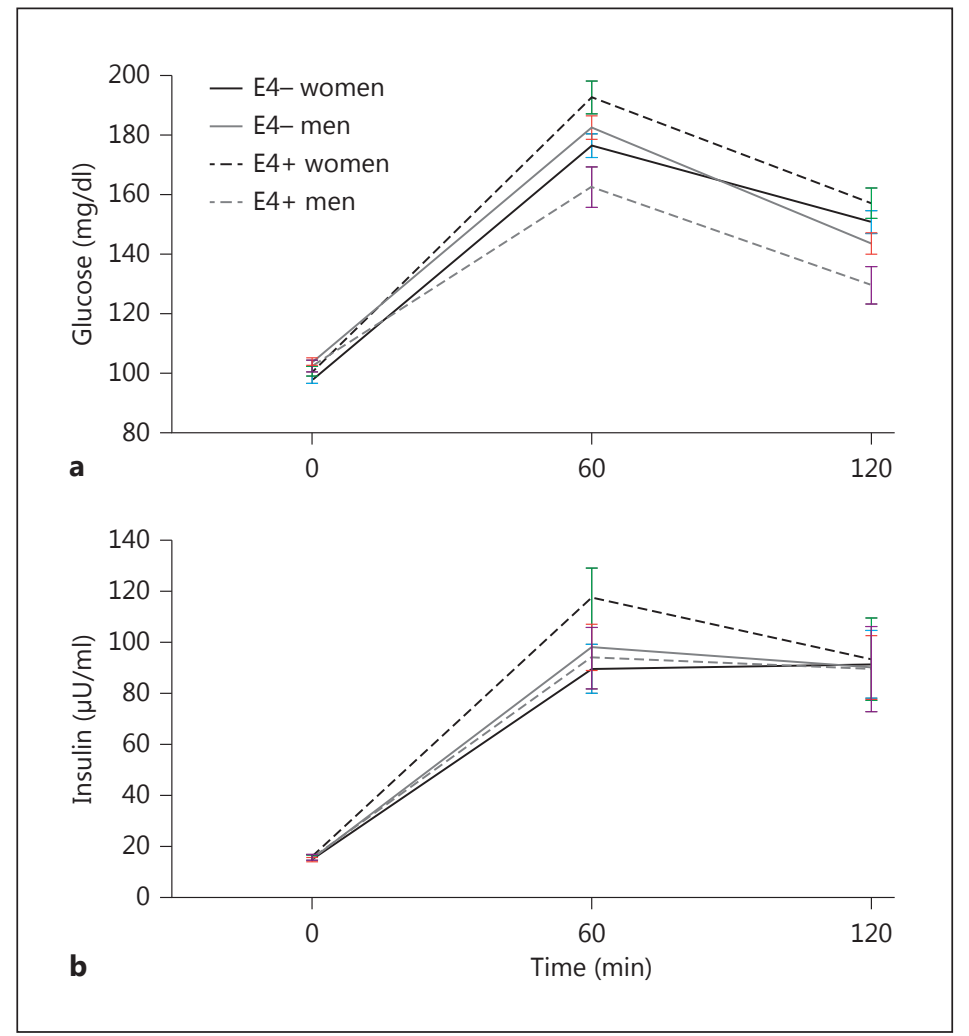

In terms of glucose, cognitive diagnosis was not significant in this model (time $\times$ diagnosis $\mathrm{p}=0.4$, table 3 ); therefore, cognitive groups were combined. The sex and $\mathrm{E} 4 \times$ sex interactions were significant factors in the overall model (time $\times$ sex $\mathrm{p}<0.0001$, time $\times \mathrm{E} 4 \times$ sex $\mathrm{p}=0.0037$ ). Exploring the time points individually, we again noted that men had significantly higher fasting glucose levels than women, irrespective of E4 status ( $\operatorname{sex} p=0.013$ ). However, an interesting pattern emerged during the OGTT (fig. 1a). For the E4- participants, the sex difference disappeared at 60 and $120 \mathrm{~min}(60 \mathrm{~min} \mathrm{p}=0.29,120 \mathrm{~min} \mathrm{p}=0.17$; table 3$)$. For the $\mathrm{E} 4+$ participants, the difference between men and women reversed such that E4+ women showed the highest glucose levels at $60 \mathrm{~min}$, whereas the E4+ men showed the lowest levels $(\mathrm{p}=0.0006)$, and this pattern persisted at $120 \mathrm{~min}(\mathrm{p}=0.0008)$.

Next, we examined the effects of cognitive diagnosis, E4 status, and sex on OGTT-induced insulin (fig. $1 \mathrm{~b}$; table 3). Given the smaller number of participants who had insulin values at 60 and $120 \mathrm{~min}$, we were unable to examine all three class variables in the model. Therefore, we analyzed cognitive diagnosis, first in isolation and then separately with sex and E4 status, in the repeated-measures model. Despite having higher fasting insulin levels, those with CI had similar insulin levels at 60 and $120 \mathrm{~min}$ to NC (time $\times$ diagnosis $\mathrm{p}=0.64$ ); therefore, cognitive groups were combined. Unlike glucose levels, insulin values did not differ by sex or $\mathrm{E} 4$ status in the overall model (time $\times \operatorname{sex~} \mathrm{p}=0.8$, time $\times \mathrm{E} 4 \times \operatorname{sex} \mathrm{p}=0.32$ ). Examination of the individual time points showed that E4+ women tended toward higher insulin levels at 60 min than E4- women $(\mathrm{p}=0.062)$. OGTT insulin levels were similar for E4+ and E4- men, despite their significant differences in OGTT glucose values. For example at $60 \mathrm{~min}$, the average insulin level for E4- men was $98 \pm 9.1 \mu \mathrm{U} / \mathrm{ml}$, and for E4+ men it was $93.8 \pm 12.1 \mu \mathrm{U} /$ $\mathrm{ml}(\mathrm{p}=0.78)$. To ensure that the subset of participants with insulin data did not differ with respect to glucose patterns, the glucose analyses were re-run with only those who had OGTT insulin, and the results were unchanged (data not shown). 
Hanson et al.: Apolipoprotein E Genotype and Sex Influence Glucose Tolerance in Older Adults: A Cross-Sectional Study

Table 3. OGTT measures

\begin{tabular}{|c|c|c|c|c|c|c|c|c|}
\hline & \multicolumn{2}{|l|}{ E4- } & \multirow{2}{*}{$\begin{array}{l}\text { p value } \\
\text { (women } \\
\text { vs. men) }{ }^{1}\end{array}$} & \multicolumn{2}{|l|}{$\mathrm{E} 4+$} & \multirow{2}{*}{$\begin{array}{l}\text { p value } \\
\text { (women } \\
\text { vs. men) }{ }^{1}\end{array}$} & \multirow{2}{*}{$\begin{array}{l}\text { p value } \\
\text { (women } \\
\text { E4+ vs. E4-) }{ }^{2}\end{array}$} & \multirow{2}{*}{$\begin{array}{l}\mathrm{p} \text { value } \\
\text { (men } \\
\text { E4+ vs. E4-) }{ }^{2}\end{array}$} \\
\hline & women & men & & women & men & & & \\
\hline Glu0 & $97.8 \pm 1.2$ & $103.9 \pm 1.2$ & 0.0004 & $100.7 \pm 1.6$ & $102.5 \pm 2$ & 0.49 & 0.16 & 0.54 \\
\hline Glu60 & $176.5 \pm 4.1$ & $182.6 \pm 3.9$ & 0.29 & $192.7 \pm 5.5$ & $162.5 \pm 6.8$ & 0.0006 & 0.019 & 0.0098 \\
\hline Glu120 & $150.9 \pm 3.8$ & $143.6 \pm 3.6$ & 0.17 & $157.1 \pm 5.1$ & $129.5 \pm 6.3$ & 0.0008 & 0.33 & 0.051 \\
\hline Ins0 & $15 \pm 0.8$ & $15 \pm 0.8$ & 0.98 & $15.8 \pm 1$ & $16 \pm 1.1$ & 0.88 & 0.52 & 0.44 \\
\hline Ins60 & $89.6 \pm 9.6$ & $98 \pm 9.1$ & 0.53 & $117.4 \pm 11.6$ & $93.8 \pm 12.1$ & 0.17 & 0.062 & 0.78 \\
\hline Ins120 & $91.4 \pm 13.3$ & $90.1 \pm 12.5$ & 0.94 & $93.4 \pm 16$ & $89.6 \pm 16.7$ & 0.87 & 0.92 & 0.98 \\
\hline
\end{tabular}

Glu0 = Fasting glucose; Glu 60 = glucose at $60 \mathrm{~min}$; Glu120 = glucose at $120 \mathrm{~min}$; Ins0 = fasting insulin; Ins60 = insulin at 60 min; Ins120 = insulin at $120 \mathrm{~min}$. Glucose (mg/dl) and insulin $(\mu \mathrm{U} / \mathrm{ml})$ values are presented by E4 status and sex at 0,60 , and $120 \mathrm{~min}$. For glucose, there was a time $\times$ sex effect $(\mathrm{p}<0.0001)$, and a time $\times \mathrm{E} 4 \times$ sex effect $(\mathrm{p}=0.0037)$. For insulin, there was a time $\times$ sex effect $(p=0.8)$ and a time $\times E 4 \times$ sex effect $(p=0.32)$. All values are presented as means \pm SEM and adjusted for age and BMI.

${ }^{1}$ Presented here are $\mathrm{p}$ values from the least-squares means comparisons for each time point comparing sex within each E4 group.

${ }^{2}$ Presented here are p values from the least-squares means comparisons for each time point comparing E4 status within each sex group.

Table 4. Correlation matrix for the entire group

\begin{tabular}{|c|c|c|c|c|c|}
\hline & Glu0 & Glu60 & Glu120 & Ins0 & HOMA \\
\hline \multirow[t]{2}{*}{ Age } & $0.201(0.0003)$ & $0.227(<0.0001)$ & $0.261(<0.0001)$ & $-0.149(0.035)$ & $-0.126(0.075)$ \\
\hline & 319 & 319 & 319 & 202 & 202 \\
\hline \multirow[t]{2}{*}{ BMI } & $0.118(0.035)$ & $0.046(0.408)$ & $0.074(0.188)$ & $0.338(<0.0001)$ & $0.357(<0.0001)$ \\
\hline & 319 & 319 & 319 & 202 & 202 \\
\hline \multirow[t]{2}{*}{ MMSE } & $0.01(0.905)$ & $-0.069(0.414)$ & $-0.181(0.031)$ & $0.01(0.906)$ & $0.028(0.743)$ \\
\hline & 142 & 142 & 142 & 140 & 140 \\
\hline \multirow[t]{2}{*}{$\mathrm{A} \beta_{42}$} & $0.322(0.0003)$ & 0.15 (0.099) & $0.233(0.01)$ & $0.061(0.532)$ & $0.106(0.281)$ \\
\hline & 123 & 123 & 123 & 106 & 106 \\
\hline
\end{tabular}

Glu0 = Fasting glucose; Glu 60 = glucose at $60 \mathrm{~min}$; Glu120 = glucose at $120 \mathrm{~min}$; Ins0 = fasting insulin. Numbers given are Pearson correlation statistics with $\mathrm{p}$ values in parentheses, and number of subjects in each comparison listed underneath. Correlations with $p$ values $<0.05$ are shown in bold.

\section{Correlations}

We next wanted to determine whether E4 status and sex influenced the relationships between metabolic measures of glucose and insulin and age, BMI, and AD-related markers of MMSE and plasma $A \beta_{42}$, using Pearson correlation statistics. These analyses were performed on a subset of patients for whom we had MMSE scores $(n=142)$ and $A \beta_{42}(n=123)$. We included glucose at 0,60 , and $120 \mathrm{~min}$, insulin at $0 \mathrm{~min}$, and HOMA-IR. We did not include insulin at 60 and $120 \mathrm{~min}$ because these data sets were underpowered. All significant patterns were examined by scatter plot, and were not caused by outliers. Significant findings were re-run controlling for cognitive diagnosis, which did not change the pattern of results; therefore, cognitive groups were combined.

Table 4 shows Pearson correlations for age, $\mathrm{BMI}, \mathrm{MMSE}$, and $\mathrm{A} \beta_{42}$ regressed against fasting glucose, glucose at $60 \mathrm{~min}$, glucose at $120 \mathrm{~min}$, fasting insulin, and HOMA. Ten of the possible 20 relations were significant. For all participants, age positively correlated with fasting glucose, 
Table 5. Correlation matrices for each E4 and sex group

\begin{tabular}{|c|c|c|c|c|c|}
\hline & Glu0 & Glu60 & Glu120 & Ins0 & HOMA \\
\hline \multicolumn{6}{|c|}{ E4-women } \\
\hline \multirow[t]{2}{*}{ Age } & $0.115(0.263)$ & $0.384(0.0001)$ & $0.272(0.007)$ & $-0.065(0.631)$ & $-0.037(0.786)$ \\
\hline & 96 & 96 & 96 & 58 & 58 \\
\hline \multirow[t]{2}{*}{ BMI } & $0.137(0.182)$ & $0.051(0.62)$ & $0.149(0.149)$ & $0.393(0.002)$ & $0.395(0.002)$ \\
\hline & 96 & 96 & 96 & 58 & 58 \\
\hline \multirow[t]{2}{*}{ MMSE } & $-0.132(0.418)$ & $-0.189(0.243)$ & $-0.248(0.124)$ & $-0.086(0.599)$ & $-0.091(0.576)$ \\
\hline & 40 & 40 & 40 & 40 & 40 \\
\hline \multirow[t]{2}{*}{$\mathrm{A} \beta_{42}$} & $0.414(0.007)$ & $0.338(0.031)$ & $0.245(0.122)$ & $-0.144(0.416)$ & $-0.061(0.733)$ \\
\hline & 41 & 41 & 41 & 34 & 34 \\
\hline \multicolumn{6}{|c|}{ E4-men } \\
\hline \multirow[t]{2}{*}{ Age } & $0.16(0.091)$ & $0.113(0.236)$ & $0.339(0.0003)$ & $-0.234(0.04)$ & $-0.242(0.034)$ \\
\hline & 112 & 112 & 112 & 77 & 77 \\
\hline \multirow[t]{2}{*}{ BMI } & $0.173(0.068)$ & $0.091(0.338)$ & $0.054(0.574)$ & $0.318(0.005)$ & $0.371(0.0009)$ \\
\hline & 112 & 112 & 112 & 77 & 77 \\
\hline \multirow[t]{2}{*}{ MMSE } & $-0.003(0.982)$ & $-0.211(0.15)$ & $-0.14(0.344)$ & $0.02(0.897)$ & $0.03(0.843)$ \\
\hline & 48 & 48 & 48 & 46 & 46 \\
\hline \multirow[t]{2}{*}{$\mathrm{A} \beta_{42}$} & $0.306(0.023)$ & $0.118(0.392)$ & $0.239(0.078)$ & $0.134(0.362)$ & $0.179(0.223)$ \\
\hline & 55 & 55 & 55 & 48 & 48 \\
\hline \multicolumn{6}{|c|}{ E4+ women } \\
\hline \multirow[t]{2}{*}{ Age } & $0.111(0.397)$ & $0.407(0.001)$ & $0.378(0.003)$ & $-0.083(0.636)$ & $-0.065(0.71)$ \\
\hline & 60 & 60 & 60 & 35 & 35 \\
\hline \multirow[t]{2}{*}{ BMI } & $0.014(0.913)$ & $-0.027(0.84)$ & $0.006(0.965)$ & $0.122(0.484)$ & $0.141(0.42)$ \\
\hline & 60 & 60 & 60 & 35 & 35 \\
\hline \multirow[t]{2}{*}{ MMSE } & $0.085(0.67)$ & $-0.025(0.901)$ & $-0.189(0.337)$ & $-0.25(0.2)$ & $-0.219(0.263)$ \\
\hline & 28 & 28 & 28 & 28 & 28 \\
\hline \multirow[t]{2}{*}{$\mathrm{A} \beta_{42}$} & $0.314(0.219)$ & $-0.005(0.986)$ & $0.28(0.277)$ & $0.396(0.144)$ & $0.501(0.057)$ \\
\hline & 17 & 17 & 17 & 15 & 15 \\
\hline \multicolumn{6}{|c|}{ E4+ men } \\
\hline \multirow[t]{2}{*}{ Age } & $0.224(0.113)$ & $0.002(0.992)$ & $0.161(0.26)$ & $-0.364(0.041)$ & $-0.328(0.067)$ \\
\hline & 51 & 51 & 51 & 32 & 32 \\
\hline \multirow[t]{2}{*}{ BMI } & $0.026(0.855)$ & $0.058(0.684)$ & $0.014(0.921)$ & $0.437(0.012)$ & $0.37(0.037)$ \\
\hline & 51 & 51 & 51 & 32 & 32 \\
\hline \multirow[t]{2}{*}{ MMSE } & $0.234(0.251)$ & $0.246(0.226)$ & $-0.209(0.305)$ & $0.374(0.06)$ & $0.392(0.048)$ \\
\hline & 26 & 26 & 26 & 26 & 26 \\
\hline \multirow[t]{2}{*}{$\bar{A} \beta_{42}$} & $0.25(0.486)$ & $-0.165(0.648)$ & $0.117(0.748)$ & $-0.476(0.195)$ & $-0.39(0.3)$ \\
\hline & 10 & 10 & 10 & 9 & 9 \\
\hline
\end{tabular}

Glu0 = Fasting glucose; Glu 60 = glucose at $60 \mathrm{~min}$; Glu120 = glucose at $120 \mathrm{~min}$; Ins 0 = fasting insulin. Pearson correlation statistics with $\mathrm{p}$ values in parentheses, and number of subjects in each comparison listed underneath. Correlations with $\mathrm{p}$ values $<0.05$ are shown in bold.

glucose at $60 \mathrm{~min}$, and glucose at $120 \mathrm{~min}$, and inversely correlated with fasting insulin. BMI positively correlated with fasting glucose, insulin, and HOMA-IR. We also noted that higher values on an OGTT were associated with higher plasma $A \beta_{42}$ levels and lower MMSE scores.

Next, individual E4 and sex groups were examined, and we found that different patterns segregated with different E4-sex groups (table 5; fig. 2). For the E4- women and men, BMI positively correlated with fasting insulin as well as with HOMA-IR, and the E4- men showed an additional inverse correlation with age and fasting insulin. Also, for both E4- women and men, age positively correlated with glucose at 120 min. Finally, for both groups, fasting $A \beta_{42}$ 
Fig. 2. Highlights of the correlation patterns among the four groups.
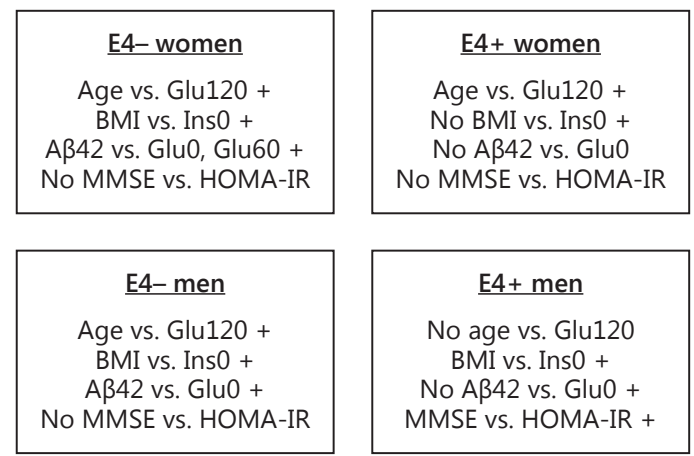

positively correlated with fasting glucose, and the E4- women showed an additional positive correlation between fasting $A \beta_{42}$ and glucose at $60 \mathrm{~min}$. As presented earlier, these two groups differed only in fasting glucose, but had similar fasting $\mathrm{A} \beta_{42}$ and similar OGTT glucose values. For the E4+ groups, different patterns were identified. For E4+ women, who displayed the highest OGTT glucose values compared to the other groups, we noted a positive correlation between age and OGTT glucose values at $120 \mathrm{~min}$. However, unlike for E4- women, we did not observe a correlation between BMI and fasting insulin, or between $A \beta_{42}$ and fasting glucose. For the E4+ men, who had the lowest OGTT glucose values, there was a correlation between BMI and fasting insulin, but no correlation between age and glucose measures, or between $A \beta_{42}$ and fasting glucose. In addition, this group showed a positive correlation between MMSE and HOMA-IR.

\section{Discussion}

\section{Summary of Findings}

In our study of older adults with $\mathrm{CI}$, we found evidence for insulin resistance in those with $\mathrm{CI}$, that sex influenced basal glucose and insulin levels, and that sex and APOE genotype influenced OGTT glucose results. In particular, we noted that E4+ women displayed the highest whereas E4+ men displayed the lowest OGTT glucose values, and that the relationships between elevated glucose levels and AD risk factors differed among the E4+ and E4- groups.

\section{$A D$ and Glucose and Insulin Metabolism}

Peripheral insulin resistance and glucose intolerance are risk factors for developing AD $[3,22,23]$. People with AD have a form of insulin resistance characterized by higher fasting insulin, abnormal insulin responses to a glucose load, elevated markers of insulin resistance in the brain, and increasing insulin required to have an effect on cognitive changes, than normal controls $[5,6,8,21]$. Here, we confirmed that individuals with $\mathrm{CI}$ had higher fasting insulin than those with $\mathrm{NC}$, and this finding was noted for both the $\mathrm{MCI}$ and AD groups, suggesting that insulin resistance may develop early in the disease process. This finding also held for all E4 $\times$ sex group comparisons, with the exception of E4- men who tended to have similar fasting insulin levels despite their cognitive diagnosis. We did not detect any differences in OGTT glucose and insulin levels between the cognitive groups. Others have noted similar OGTT glucose values for AD patients compared to controls; however, one group noted higher OGTT insulin levels in those with $\mathrm{AD}[24,25]$. 


\section{APOE Influences on AD and Glucose and Insulin Metabolism}

Prolonged peripheral hyperinsulinemia is associated with decreases in CSF insulin levels, which could then impair amyloid clearance and neuronal signaling $[3,4,26]$. However, this inverse relationship between peripheral and brain insulin is less robust in $\mathrm{E} 4$ carriers. Fasting hyperinsulinemia and low early insulin release were associated with an increased risk of AD, but only in E4- adults [7, 8]. Although both E4+ and E4- groups with AD demonstrated low CSF insulin, only E4- individuals showed a relationship between CSF and plasma insulin, and between CSF A $\beta$ and plasma insulin and glucose measures [6, 9]. Importantly, E4+ individuals demonstrated less cognitive benefit from insulin-related therapeutics for AD including insulin infusions, the insulin sensitizer rosiglitazone, and regular and rapid-acting intranasal insulin [10-14]. Conversely, long-acting intranasal detemir insulin improved cognition and reduced peripheral insulin resistance in E4+ participants, whereas E4- individuals showed opposite results [27]. Whether E4 status influences treatment response may also depend on the patients' sex. In a responder analysis of higher doses of regular intranasal insulin, E4- men improved on memory testing, E4- women worsened, and E4+ groups showed no effect [15]. In summary, the relationship between brain insulin, peripheral insulin, and AD biomarkers depends on the E4 status, and may be further modulated by sex.

In our sample of older adults, we noted that men had higher fasting glucose levels than women, but that response to a glucose stressor depended on both the E4+ status and sex. Others have similarly reported that men have higher rates of impaired fasting glucose than women, whereas women have higher postprandial glucose levels [28]. It is known that E4+ status increases the risk of hyperlipidemia; less is known about its influence on glucose and insulin metabolism [29]. The majority of studies have found that the APOE genotype does not influence fasting glucose and insulin levels, consistent with our data [30,31]. Studies examining APOE and OGTT have shown mixed results. A study in American Indian adults noted higher 2-hour OGTT glucose levels in E4+ compared to E3+ women, and nonsignificantly lower glucose values in E4+ men, similar to our findings [31]. Others have shown that E4+ men have higher OGTT glucose and insulin; however, rates of diabetes were higher in some E4+ groups [32-34]. In our sample, which differed from other studies by the inclusion of individuals with $\mathrm{CI}$ and the exclusion of diabetics, E4+ women displayed higher glucose excursions compared to E4- men and women, and we observed that E4+ men showed the lowest level, in response to a glucose stressor. Interestingly, E4+ men demonstrated OGTT insulin levels similar to the other groups, suggesting that glucose differences may be driven by factors other than insulin secretion. Craft et al. [11] demonstrated that E4- patients with AD had lower insulin-mediated glucose disposal rates than E4+ patients, yet similar C peptide levels, indicating that differential insulin clearance rates could account for E4-specific responses to insulin infusions. Given that the mechanisms for how peripheral insulin resistance leads to increased $\mathrm{AD}$ are not completely understood, it is unknown how E4 carrier status might modulate these mechanisms. One potential mechanism is that due to differences in lipid metabolism in E4+ individuals (here, particularly E4+ men), they may be insulin sensitive at baseline, and therefore unable to benefit from insulin sensitizers impacting on brain function. Formal analysis of glucose and insulin metabolism, such as hyperglycemic clamp data, would help confirm these findings and establish potential mechanisms for E4-related differences.

\section{Relationship between Glucose Tolerance and AD Risk Factors}

Our correlation patterns suggest that in this group of older adults with AD risk factors and $\mathrm{CI}$, we see the known associations between age, BMI, and glucose metabolism markers, such as BMI correlating with HOMA, fasting insulin, and fasting glucose. Interestingly, only aspects of these overall relations were found in subset analyses, and these tended to segregate with regard to sex and APOE genotype. Although loss of correlations may be caused in part 
Hanson et al.: Apolipoprotein E Genotype and Sex Influence Glucose Tolerance in Older Adults: A Cross-Sectional Study

by the decreased power in subset analyses, this, in turn, makes those preserved trends even more intriguing. For example, age is a known risk factor for AD and for impaired glucose tolerance [35], and in all groups, except E4+ men, age positively correlated with OGTT glucose values. In addition, E4+ men showed an inverse association between MMSE and HOMA-IR scores such that higher insulin resistance was associated with higher MMSE scores. For E4+ women, who had the highest OGTT glucose values, they did not show an association between BMI and fasting glucose and insulin measures. The APOE genotype also influenced the relationship between plasma $A \beta_{42}$ and fasting glucose. For both E4- groups, higher $A \beta_{42}$ was associated with higher fasting glucose. These relationships were not seen for the E4+ groups. These results suggest that traditional risk factors for glucose intolerance may not be as strongly associated in E4+ individuals, which may explain, in part, why glucose and insulin metabolic abnormalities are not as strongly linked to $\mathrm{CI}$ in this group. In addition, recent longitudinal studies have shown that E4 carrier status is a stronger risk factor for women than for men [16]. Further analyses of known insulin resistance risk factors, such as age, BMI, and abdominal adiposity in E4+ and E4- men and women, would help clarify these findings.

\section{Plasma $A \beta$ and Glucose Metabolism}

Elevated OGTT glucose and fasting insulin were associated with increased amyloid plaques in one autopsy study [36]. Experimental evidence supports this association, as an oral glucose load increased plasma A $\beta$ levels in adults with AD [37]. As noted with insulin, this association between glucose intolerance and amyloid may be limited to E4-individuals. Only E4- individuals showed a relationship between CSF A $\beta$ and the CSF-to-plasma glucose ratio [27]; moreover, in E4- individuals, memory improvement and a reduction in plasma amyloid precursor protein were observed in response to insulin infusion; E4+ adults had no changes in memory, and their plasma amyloid precursor protein increased in response to insulin [10]. As noted above, there was a correlation between higher plasma $A \beta_{42}$ and higher fasting glucose in E4- men and women, and with higher OGTT glucose values in E4- women; these correlations were absent in the E4+ groups. These data continue to support a pathologic link between insulin resistance, glucose intolerance, and increases in pathologic $A \beta$, but suggest that the link is predominantly limited to E4- individuals.

\section{Limitations/Future Directions}

Limitations of this study include that this was a post hoc analysis of a convenience sample of several different studies, and the studies were not designed initially to examine the E4 and sex groups a priori, limiting the ability to generalize results. We did not have enough data at 30 min to calculate some of the known measures derived from an OGTT, such as the oral disposition index [38]. Further interventional studies examining more detailed OGTT responses, such as early- versus late-phase insulin secretion, would be informative. In addition, we did not have data on CSF measures, and future studies looking at CSF biomarkers including A $\beta$, insulin, and other brain-related markers of insulin function would be useful to confirm these findings and expound on their significance to AD. Analysis of human experimental data in response to insulin treatments as well as APOE-specific animal models of AD will help us further understand the role of insulin in brain functions and how this may differ by APOE genotype.

\section{Conclusions}

Insulin resistance is a risk factor for developing $\mathrm{AD}$, and treatments which improve brain insulin signaling are promising. However, E4+ individuals, who are at a higher risk of developing $\mathrm{AD}$, do not respond as robustly to insulin-related $\mathrm{AD}$ therapies and do not show as 
strong a link between peripheral insulin resistance and AD. Here, we continue to show evidence of insulin resistance in those with $\mathrm{AD}$ and those with CI likely to develop to AD. In addition, we found that E4 status and sex influence glucose tolerance in older adults, as E4+ women had higher and E4+ men had lower glucose values on an OGTT despite similar levels of insulin. We also show that E4 status attenuates correlations between OGTT glucose values and age, MMSE, and plasma $\mathrm{A} \beta_{42}$. Understanding how the APOE genotype influences peripheral glucose and insulin metabolism may help us understand why E4+ carrier status is a higher risk factor for women than for men, and why E4+ individuals respond less favorably to insulinrelated therapeutics for AD.

\section{Acknowledgements}

This research was supported by the 5T32AG000258 training grant and AFAR Hartford Center of Excellence Award to Dr. Hanson. This article results from work supported by resources from the Veterans Affairs Puget Sound Health Care System, Seattle, Wash., USA.

\section{References}

1 Liu CC, Kanekiyo T, Xu H, Bu G: Apolipoprotein E and Alzheimer disease: risk, mechanisms and therapy. Nat Rev Neurol 2013;9:106-118.

2 Barnes DE, Yaffe K: The projected effect of risk factor reduction on Alzheimer's disease prevalence. Lancet Neurol 2011;10:819-828.

3 Cholerton B, Baker LD, Craft S: Insulin resistance and pathological brain ageing. Diabet Med 2011;28:14631475.

-4 Thambisetty M, Beason-Held LL, An Y, Kraut M, Metter J, Egan J, Ferrucci L, O’Brien R, Resnick SM: Impaired glucose tolerance in midlife and longitudinal changes in brain function during aging. Neurobiol Aging 2013; 34:2271-2276.

5 Talbot K, Wang HY, Kazi H, Han LY, Bakshi KP, Stucky A, Fuino RL, Kawaguchi KR, Samoyedny AJ, Wilson RS, Arvanitakis Z, Schneider JA, Wolf BA, Bennett DA, Trojanowski JQ, Arnold SE: Demonstrated brain insulin resistance in Alzheimer's disease patients is associated with IGF-1 resistance, IRS-1 dysregulation, and cognitive decline. J Clin Invest 2012;122:1316-1338.

6 Craft S, Peskind E, Schwartz MW, Schellenberg GD, Raskind M, Porte D Jr: Cerebrospinal fluid and plasma insulin levels in Alzheimer's disease: relationship to severity of dementia and apolipoprotein E genotype. Neurology 1998;50:164-168.

7 Kuusisto J, Koivisto K, Mykkanen L, Helkala EL, Vanhanen M, Hanninen T, Kervinen K, Kesaniemi YA, Riekkinen PJ, Laakso M: Association between features of the insulin resistance syndrome and Alzheimer's disease independently of apolipoprotein E4 phenotype: cross sectional population based study. BMJ 1997;315:10451049.

8 Ronnemaa E, Zethelius B, Sundelof J, Sundstrom J, Degerman-Gunnarsson M, Berne C, Lannfelt L, Kilander L: Impaired insulin secretion increases the risk of Alzheimer disease. Neurology 2008;71:1065-1071.

-9 Dumurgier J, Paquet C, Peoc'h K, Lapalus P, Mouton-Liger F, Benisty S, Chasseigneaux S, Chabriat H, Hugon J: CSF A $\beta_{1-42}$ levels and glucose metabolism in Alzheimer's disease. J Alzheimers Dis 2011;27:845-851.

10 Craft S, Asthana S, Schellenberg G, Baker L, Cherrier M, Boyt AA, Martins RN, Raskind M, Peskind E, Plymate S: Insulin effects on glucose metabolism, memory, and plasma amyloid precursor protein in Alzheimer's disease differ according to apolipoprotein-E genotype. Ann NY Acad Sci 2000;903:222-228.

11 Craft S, Asthana S, Schellenberg G, Cherrier M, Baker LD, Newcomer J, Plymate S, Latendresse S, Petrova A, Raskind M, Peskind E, Lofgreen C, Grimwood K: Insulin metabolism in Alzheimer's disease differs according to apolipoprotein E genotype and gender. Neuroendocrinology 1999;70:146-152.

12 Reger MA, Watson GS, Frey WH 2nd, Baker LD, Cholerton B, Keeling ML, Belongia DA, Fishel MA, Plymate SR, Schellenberg GD, Cherrier MM, Craft S: Effects of intranasal insulin on cognition in memory-impaired older adults: modulation by APOE genotype. Neurobiol Aging 2006;27:451-458.

13 Risner ME, Saunders AM, Altman JF, Ormandy GC, Craft S, Foley IM, Zvartau-Hind ME, Hosford DA, Roses AD: Efficacy of rosiglitazone in a genetically defined population with mild-to-moderate Alzheimer's disease. Pharmacogenomics J 2006;6:246-254.

14 Rosenbloom MH, Barclay TR, Pyle M, Owens BL, Cagan AB, Anderson CP, Frey WH 2nd, Hanson LR: A singledose pilot trial of intranasal rapid-acting insulin in apolipoprotein E4 carriers with mild-moderate Alzheimer's disease. CNS Drugs 2014;28:1185-1189. 
Claxton A, Baker LD, Wilkinson CW, Trittschuh EH, Chapman D, Watson GS, Cholerton B, Plymate SR, Arbuckle M, Craft S: Sex and ApoE genotype differences in treatment response to two doses of intranasal insulin in adults with mild cognitive impairment or Alzheimer's disease. J Alzheimers Dis 2013;35:789-797.

$\checkmark 16$ Altmann A, Tian L, Henderson VW, Greicius MD: Sex modifies the APOE-related risk of developing Alzheimer disease. Ann Neurol 2014;75:563-573.

-17 Baker LD, Cross DJ, Minoshima S, Belongia D, Watson GS, Craft S: Insulin resistance and Alzheimer-like reductions in regional cerebral glucose metabolism for cognitively normal adults with prediabetes or early type 2 diabetes. Arch Neurol 2011;68:51-57.

$>18$ Kuzuya H, Blix PM, Horwitz DL, Steiner DF, Rubenstein AH: Determination of free and total insulin and C-peptide in insulin-treated diabetics. Diabetes 1977;26:22-29.

19 Ascaso JF, Pardo S, Real JT, Lorente RI, Priego A, Carmena R: Diagnosing insulin resistance by simple quantitative methods in subjects with normal glucose metabolism. Diabetes Care 2003;26:3320-3325.

20 Hixson JE, Vernier DT: Restriction isotyping of human apolipoprotein E by gene amplification and cleavage with HhaI. J Lipid Res 1990;31:545-548.

21 Craft S: Insulin resistance and Alzheimer's disease pathogenesis: potential mechanisms and implications for treatment. Curr Alzheimer Res 2007;4:147-152.

-22 Rawlings AM, Sharrett AR, Schneider AL, Coresh J, Albert M, Couper D, Griswold M, Gottesman RF, Wagenknecht LE, Windham BG, Selvin E: Diabetes in midlife and cognitive change over 20 years: a cohort study. Ann Intern Med 2014;161:785-793.

-23 Crane PK, Walker R, Hubbard RA, Li G, Nathan DM, Zheng H, Haneuse S, Craft S, Montine TJ, Kahn SE, McCormick W, McCurry SM, Bowen JD, Larson EB: Glucose levels and risk of dementia. N Engl J Med 2013;369:540-548.

24 Takeda S, Sato N, Uchio-Yamada K, Yu H, Moriguchi A, Rakugi H, Morishita R: Oral glucose loading modulates plasma beta-amyloid level in Alzheimer's disease patients: potential diagnostic method for Alzheimer's disease. Dement Geriatr Cogn Disord 2012;34:25-30.

25 Thambisetty M, Jeffrey Metter E, Yang A, Dolan H, Marano C, Zonderman AB, Troncoso JC, Zhou Y, Wong DF, Ferrucci L, Egan J, Resnick SM, O’Brien RJ: Glucose intolerance, insulin resistance, and pathological features of Alzheimer disease in the Baltimore Longitudinal Study of Aging. JAMA Neurol 2013;70:1167-1172.

26 Banks WA, Owen JB, Erickson MA: Insulin in the brain: there and back again. Pharmacol Ther 2012;136:82-93. Claxton A, Baker LD, Hanson A, Trittschuh EH, Cholerton B, Morgan A, Callaghan M, Arbuckle M, Behl C, Craft S: Long-acting intranasal insulin detemir improves cognition for adults with mild cognitive impairment or early-stage Alzheimer's disease dementia. J Alzheimers Dis 2015;45:1269-1270.

28 Blaak E: Sex differences in the control of glucose homeostasis. Curr Opin Clin Nutr Metab Care 2008;11:500504.

29 Bennet AM, Di Angelantonio E, Ye Z, Wensley F, Dahlin A, Ahlbom A, Keavney B, Collins R, Wiman B, de Faire U, Danesh J: Association of apolipoprotein E genotypes with lipid levels and coronary risk. JAMA 2007;298: 1300-1311.

-30 Guerra A, Rego C, Castro EM, Seixas S, Rocha J: Influence of apolipoprotein E polymorphism on cardiovascular risk factors in obese children. Ann Nutr Metab 2003;47:49-54.

-31 Kataoka S, Robbins DC, Cowan LD, Go O, Yeh JL, Devereux RB, Fabsitz RR, Lee ET, Welty TK, Howard BV: Apolipoprotein E polymorphism in American Indians and its relation to plasma lipoproteins and diabetes. The Strong Heart Study. Arterioscler Thromb Vasc Biol 1996;16:918-925.

-32 Valdez R, Howard BV, Stern MP, Haffner SM: Apolipoprotein E polymorphism and insulin levels in a biethnic population. Diabetes Care 1995;18:992-1000.

-33 Elosua R, Demissie S, Cupples LA, Meigs JB, Wilson PW, Schaefer EJ, Corella D, Ordovas JM: Obesity modulates the association among APOE genotype, insulin, and glucose in men. Obes Res 2003;11:1502-1508.

-34 Helkala EL, Lakka T, Vanhanen M, Tuomainen TP, Ehnholm C, Kaplan GA, Salonen JT: Associations between apolipoprotein E phenotype, glucose metabolism and cognitive function in men. An explorative study in a population sample. Diabet Med 2001;18:991-997.

-35 Chang AM, Halter JB: Aging and insulin secretion. Am J Physiol Endocrinol Metab 2003;284:E7-E12.

-36 Matsuzaki T, Sasaki K, Tanizaki Y, Hata J, Fujimi K, Matsui Y, Sekita A, Suzuki SO, Kanba S, Kiyohara Y, Iwaki T: Insulin resistance is associated with the pathology of Alzheimer disease: the Hisayama study. Neurology 2010; 75:764-770.

-37 Takeda S, Sato N, Rakugi H, Morishita R: Plasma beta-amyloid as potential biomarker of Alzheimer disease: possibility of diagnostic tool for Alzheimer disease. Mol Biosyst 2010;6:1760-1766.

-38 Utzschneider KM, Prigeon RL, Faulenbach MV, Tong J, Carr DB, Boyko EJ, Leonetti DL, McNeely MJ, Fujimoto WY, Kahn SE: Oral disposition index predicts the development of future diabetes above and beyond fasting and 2-h glucose levels. Diabetes Care 2009;32:335-341. 